\title{
NOTÍCIA DA CULTURA INDUSTRIAL DA GUAXIMA NO BRASIL NOS FINS DO SÉCULO XVIII.
}

Sôbre a utilização econômica da guaxima no Brasil, não se tem conhecimento de notícias anteriores aos fins do século XVIII. Desconhecemos quaisquer achegas referentes à sua cultura industrial antes de 1778. Tudo indica que os primeiros ensaios do aproveitamento econômico desta planta brasileira datam, realmente, dos fins do setecentismo. Foi o Marquês do Lavradio - D. Luís de Almeida Portugal Soares Mascarenhas que, como se sabe, governou - Brasil durante o período que se estende de 1769 a 1779 - o primeiro à perceber a importância econômica da guaxima para a indústria da sacaria e cordoaria.

Numa das suas cartas - datada do Rio de Janeiro a 12 de janeiro de 1778 - à rainha $\mathrm{D}$. Maria $\mathrm{I}$, o sagaz Marquês do Lavradio insistia; junto ao govêrno de Lisbọa, para que se proporcionassem as necessárias condições de desenvolvimento da cultura industrial da guaxima brasileira.

Este curioso e instrutivo documento, de avultado valor para a incipiente História Econômica Colonial do Brasil, encontra-se guardado no Arquivo Histórico Ultramarino de Lisboa (1). Afigurase-nos que é mesmo a primeira fonte documental segura a nos ministrar notícias dos primeiros ensaios da industrialização da guaxima no Brasil. Infelizmente, as escassas monografias respeitantes à nossa mal conhecida história econômica não informam - nem sequer de longe - quaisquer notícias sôbre a cultura econômica desta planta textil brasileira. Isto só serve para aguçar a nossa curiosidade.

A darmos crédito aos informes do Marquês do Lavradio, a guaxima era planta demasiadamente comum no Brasil, crescendo, fàcilmente, em qualquer tipo de solo. Planta textil, da família das malváceas, constituia uma verdadeira praga, tamanho era o seu desenvolvimento. Crescia com incrível rapidez. Os nossos lavradores combatiam-na çomo terrivel inimiga das suas sementeiras. Os agricultores tinham necessidade de mondá-la constantemente, para que

(1). - A cota do documento é: Rio de Janeiro, Papéis Avulsos, 1778. 
suas plantações não fôssem asfixiadas por ela. Era pois, uma planta daninha para os que se dedicavam à lavoura (2).

Nas vizinhanças do Rio Grande de São Pedro êste arbusto chegava a atingir, com incrivel rapidez, 14 a 15 palmos de altura. Embora combatida pelos nossos agricultores, a guaxima era tida em boa conta pelos indigenas e negros das fazendas que aproveitavam as suas fibras para o fabrico de certas amarras e cordas com que prendiam os animais. Esta utilização da guaxima, pela indústria doméstica dos negros e indígenas, acabaria por despertar a atenção dos lavradores que passaram a vê-la como excelente combustível para aquecimento dos fornos e queima de formigueiros (3)

A incipiente indústria da cordoaria nativa chamou a si, tạmbém, os olhares do Marquês do Lavradio que, entusiasmado pelos resultados, imediatamente se empenhou, junto à rainha D. Maria I, para o aproveitamento econômico da planta brasileira. A sagacidade do nosso Vice-rei viu na guaxima uma segura fonte de renda para os cofres públicos. O Marquês não perdeu tempo. Enviou logo para Lisboa algumas amostras da planta. Fibras, cordas e sacos foram remetidos a $D$. Maria I com o elevado intuito de interessar o govêrno pòrtuguês na nova indústria, que ao Marquês do Lavradio parecia ser prometedora.

O Vice-rei foi minucioso no seu relato. Advogando a utilização econômica da guaxima, explica, a D. Maria I, a sua tecnologia fabril. Uma vez apanhada, a planta era tratada como o linho. Mergulhada na água deixava-se a cortir por algum tempo. Trabalhada, produzia um tipo de linho com que se faziam variedades de cordoalhas. As fibras da guaxima chegavam a oferecer vantagens sôbre o cânhamo, por serem menos pesadas e de maior resistência.

Os mestres das naus das rotas atlânticas do Brasil chegaram a examinar, a mando do Marquês do Lavradio, alguns cabos e certos tipos de cordas feitos de guaxima. Os resultados ultrapassaram quaisquer expectativas.

E' de se salientar o significado econômico dêstes primeiros ensaios industriais da guaxima no Brasil, quando se sabe que Portugal era ainda, a esta altura dos fins do século XVIII, um dos melhores clientes da sacaria e cordoaria holandesa. Os navios das rotas marítimas portuguêsas, particularmente os da carreira da fndia, foram sempre assiduos consumidores dos cordoeiros flamengos. Com a expansão atlântica portuguêsa, e conseqüente organização das rotas marítimas de comércio à distância, a indústria fla-

(2). - "Esta se chama guaxima, produz em todaz as terras, he preciso andar continuamente mondando as terraz para que esta planta náo embarase o cresimento das outras que forão semiadaz" (Idem, p. 2).

(3). - "com ella se aquese muita parte dos fornos, se fazem fugueiras para se queimarem frumigas, etc., aproveitão os Ind:oz e os negros fazendo dellas Humas Cordaz, dizendo acharem-na mais forte". (Ibidem). 
menga da cordoaria e sacaria viu-se enriquecida pela conquista de um maior valor exportador. Caminharam paralelas, neste e noutros setores, as economias portuguêsa e flamenga desde o apagar das Iuzes da Idade Média. Não entraremos aqui em detalhes. Eles seriam demasiadamente longos e não caberiam dentro das balisas de um pequeno artigo de revista. Ademais, seria desviar o fio da meada. Todavia, basta recordar que as Quitações de $D$. Manuel (4) - excelente manancial documental para o estudo das relações comerciais entre Portugal e a Flandres no século XVI - acusam, na contabilidade dos seus feitores do Ultramar, cordoaria flamenga apesar de, no Reino, se fabricarem bons exemplos de sacaria e cordames. Esta clientela portuguêsa manteve-se, pelo menos, até os fins do século XVIII ao ponto dos navios da rota do Brasil serem um sorvedouro de cordoames importados dos mercados industriais do Mar do Norte.

Esta efetiva situação exprime bem o avultado interêsse econômico do Marquês do Lavradio, pelo futuro da planta brasileira na aplicação industrial da sacaria e cordoaria. O seu incremento traria uma quebra nas importações destas mercadorias que se traduziria, fatalmente, num alívio para a fazenda pública, eternamente deficitária numa época como a da infeliz $D$. Maria I.

E' de se conjecturar que os espertos negociantes flamengos perceberam logo a importância industrial da guaxima brasileira. Não constituirá surprêsa saber-se que fibras da planta seriam exportadas para a Holanda. Que o Marquês do Lavradio interessou técnicos flamengos na nova indústria do Brasil Colonial não há que duvidar. E' êle próprio que o declara a D. Maria I, intercedendo junto à rainha para que se concedesse o monopólio do cultivo e da indústria da guaxima, pelo prazo de oito ou dez anos, a um negociante holandês, de nome João Hopman, que desfrutava da confiança e dos favores do nosso Vice-rei (5).

Infelizmente, nadá se sabe do sistema da exploração comercial da guaxima. Sequer temos conhecimento se o govêrno de Lisboa concedeu, realmente, a João Hopman o favor régio que the permitiria a exclusividade da cultura e indústria da preciosa planta textil brasileira. De qualquer forma é de se crer que teria haviđo uma mudança de paisagem nas regiōes onde, fartamente, crescia a guaxima. A nova planta industrial, antes mondada pelos lavradores como praga para as culturas, seria, a partir de então, encarada co-

(4). - As Cartas de Quitação de D. Manuel poderão ser vistas nos volumes do Arquivo Histórico Português. Todavia, é conveniente completálas nos Livros das Chancelarias guardados no Arquivo Nacional da Tôrre do Tombo.

(5). - "Este homem que eu empreguei hé hum Olandez Cazado, etc. Este homem se chama João Hopmen e em Lisboa achará V. Ex. infenitaz pessoaz que o poderāo informar do seu merecimento. Se a Raynha Minha Senhora quizer animar este homem danda-lhe hum exclusivo por tempo de oito ou dez annoz para que só elle possa fabricar este Linho", etc. (Idem, p. 3 ). 
mo um novo manancial de riqueza. Os agricultores substituiriam certas sementeiras pelo cultivo da guaxima, visando um lucro mais certo e mais rápido. Eis um tema de história econômica colonial do Brasil a despertar curiosidade, caso não tenham abortado os primeiros ensaios do Marquês do Lavradio para o aproveitamento industrial desta planta tão pouco conhecida da nossa flora econômica.

O Vice-Rei empenhou-se, junto ao govêrno português, para que se dessem certas terras devolutas ao holandês João Hopman para o cultivo da guaxima. Outrossim, propunha o Vicerei a D. Maria I, que a emprêsa, nos seus dois primeiros anos, devia ser financiada pela Fazenda Real. O concessionário se comprometia a entregar à Fazenda, como forma de pagamento das importâncias investidas pela Corôa, um determinado montante do produto já industrializad̆o. O govêrno de Lisbóa chamaria a si o contrôle do tráfico, fixando preços, que seriam determinados pela Junta da Fazenda do Rio de Janeiro ('6). O regime comercial oscilaria entre o monopólio - do Estado ou particular - e o comércio por particulares dependente de autorização da Corîa ou de um determinado concessionário.

Ignoramos se o govêrno de Lisboa aceitou ou não o plano ęonômico arquitetado pelo Marquês do Lavradio. Tampouco se sabe se a exportação da guaxima para o Reino era feita apenas em linho em rama, ou se a fibra já ia industrializada. Caso João Hopman tenha recebido o favor régio que the daria a privilegiada concessão, tudo indica que o cultivo e indústria da guaxima se desenvolveram ao ponto de exportarmos espécies de sacaria e cordoaria. Uma pesquisa mais paciente e prolongada poderá, sem dúvida, informar sôbre os valores e carregamentos dêste tráfico que, certamente, teria enriquecido a rota atlântica do Brasil por nos parecer que a indústria da guaxima não seria apenas de consumo interno mas de exportação, pelo menos, para o Reino. Afigura-se-nos mesmo que a guaxima teria sido, durante algum tempo, uma das mais importantes e prósperas culturas industriais do Brasil Colônia' zo ponto de concorrer com o cânhamo, e com os linhos donzela e galego, no fabrico de sacaria e cordoaria.

Sabe-se que até dezembro de 1778 , o govêrno português não tinha ainda reconhecido na planta brasileira as qualidades econômicas apregoadas pelo Marquês do Lavradio. E' o que se constata - por uma segunda carta escrita pelo nosso Vice-rei a D. Maria I, - datada do Rio de Janeiro aos 4 de dezembro dêste ano, guardada

(6). - "detreminancio a Raynha Minha Senhora que no primeiro e Segunto anno se Asista pella Sue Real Fazenda a este homem com o que the for preciso, hindo pagando a mesma Real Fazenda com o Linho que for entregando na Fazenda Real para o que se arbitrará primeiro a presoz por que se deve vender, ficando ao Cargo da Junta da Fazenda daqui". (Ibidem). 
no Arquivo Histórico Ultramarino, e que apresenta a mesma cota da primeira. O govêrno de Lisboa não se entusiasmou com as amostras da planta brasileira enviada pelo Marquês do Lavradio. Muito ao contrário, determinou ao govêrno do Brașil que desenvolvesse, de preferência, a plantação do cânhamo (7).

O Vice-rei, que via grande futuro na aplicação industrial da nossa guaxima, procurou, mais que depressa, justificar-se junto à Corôa portuguêsa, esclarecendo, a D. Maria I, quèe as amostras que enviara a Lisboa eram de fibras de plantas colhidas fora do tempo e preparadas empiricamente (8). O Brasil se tornaria, no dizer do Marquês, um novo país do linho suficientemente capaz de alimentar uma indústria de panos, sacaria e cordoaria. Ignoramos qual tenha sido a resposta do govêrno português.

Em 1779 terminou o mandato do Marquês do Lavradio. Até essa altura, pelo menos, parece-nos que o cultivo e a indústria da guaxima não se tenham desenvolvido entre nós. E' o que tudo indica. D. Maria I, a implacável inimiga do Marquês de Pombal, não teve olhos para ver na planta brasileira as qualidades econômicas apregoadas pelo Marquês do. Lavradio. Teria tido melhor sorte o novo Vice-rei, D. Luís de Vasconcelos e Souza? Nada se sabe. O desconhecimento que se tem sôbre isto, restringe mais ainda, a intenção dêste alinhavado-artigo que, simplesmente, se propõe chamar atenção da nossa historiografia para um assunto que - não só por nos parecer ignorado, mas por o julgarmos impartante - merece futuras pesquisas. Não apenas à História Econômica Colonial do Brasil, mas à nossa própria flora, se daria nova contribuição.

\section{MANUEL NUNES DIAS}

Assistente da Cadeira de História da Civilização Moderna e Contemporânea da Faculdade de Filosofia, Ciências = Letras da Universidade de São Paulo.

(7). - "Ordenando-me V. Ex. que eu promova a plantaçäo do linho Canbamo pelo modo que V. Ex. me indica no mesmo oficio". - Carta de 4 de dezembro de 1778 (Arquivo Histórico Ultramerino. Rio de Janeiro. Papéis Avulsos, 1778).

(8). - "sem os conbecimentos que sāo precizos para elle poder fazer o seo devido efeito e bem vê $v$. Ex. que não pode isto fazer hua prova täo solida contra o merecimento do mesmo linho" - Ibidem, p.5.) 